\title{
Gallbladder cancer with EGFR mutation and its response to GemOx with erlotinib: a case report and review of literature
}

\author{
Kishan Soni, Tarun Kumar and Manoj Pandey ${ }^{*}$ (D)
}

\begin{abstract}
Background: Gallbladder cancer (GBC) is the most common and aggressive extra hepatic biliary tree cancer (BTC) with dismal outcome. Complete surgical resection is the treatment of choice. Chemotherapy is used for palliation in advanced GBC where surgery is not possible, and the most commonly used agent is gemcitabine in combination with cisplatin or oxaliplatin or with capecitabine regimens. Complete remissions are hardly encountered in these cases; therefore, it is important to combine standard therapies with molecular targeting.

Case presentation: A 60-year-old woman presented with pain in abdomen and loss of appetite for 1 month, and imaging showed locally advanced gallbladder carcinoma with liver metastasis. After biopsy confirmation, patient was initially started on gemcitabine and oxaliplatin combination followed by gene sequencing, which showed Tp53 (exon 7-c.713 G > A and exon 5-c.376-2A > G) and EGFR (exon 20-T790M) mutation, and erlotinib was added to chemotherapy, after 6 cycles of chemotherapy patient showed a $90 \%$ partial radiological response as per RECIST criteria.
\end{abstract}

Conclusion: This case reports the possible efficacy of erlotinib in combination with gemcitabine and oxaliplatin in treating an EGFR-mutated GBC with liver metastasis. To our knowledge, this is the first article reporting the response to erlotinib combination therapy with this particular solitary mutation.

Keywords: Gallbladder cancer, Tyrosine kinase inhibitors, Gemcitabine, Erlotinib, Chemotherapy

\section{Introduction}

Gallbladder cancer (GBC) is the most common biliary tree cancer (BTC) with the short median survival, affecting more women than men. Higher incidence GBC has been reported from Chile, Japan, Poland, and northern India [1]. The disease is characterized by local invasion into common bile duct (CBD), liver, duodenum, and colon with or without vascular encasement, regional lymph node metastasis, and distant metastases commonly to liver and lung. Peritoneal carcinomatosis with omental and mesenteric deposits and ascitis is also

\footnotetext{
* Correspondence: manojpandey66@gmail.com Department of Surgical Oncology, Institute of Medical Sciences, Banaras Hindu University, Varanasi 221005, India
}

commonly seen. Complete surgical resection is the most preferred treatment of choice in GBC cases. However, advanced unresectable cases require chemotherapy and have a poor prognosis. Combination chemotherapy with gemcitabine and cisplatin (GC) is the standard of care for advanced BTC [2]. Complete remission is hardly encountered in these cases with chemotherapy; therefore, it is important to combine standard treatment with molecular targeted drugs.

The search for molecular targets led to identification of epidermal growth factor receptor (EGFR) and vascular endothelial growth factor receptors (VEGF) in biliary cancers [3]. Other than p53, ErbB signaling (including EGFR, HER2, ERBB3, and ERBB4) is the most commonly mutated pathway, affecting up to $36.8 \%$ of the

(c) The Author(s). 2020 Open Access This article is licensed under a Creative Commons Attribution 4.0 International License, which permits use, sharing, adaptation, distribution and reproduction in any medium or format, as long as you give appropriate credit to the original author(s) and the source, provide a link to the Creative Commons licence, and indicate if changes were made. The images or other third party material in this article are included in the article's Creative Commons. licence, unless indicated otherwise in a credit line to the material. If material is not included in the article's Creative Commons licence and your intended use is not permitted by statutory regulation or exceeds the permitted use, you will need to obtain permission directly from the copyright holder. To view a copy of this licence, visit http://creativecommons.org/licenses/by/4.0/ The Creative Commons Public Domain Dedication waiver (http://creativecommons.org/publicdomain/zero/1.0/) applies to the data made available in this article, unless otherwise stated in a credit line to the data. 
GBC [4]. The EGFR protein expression is seen in 54 to $65 \%$ of BTC [5] and is found to be associated with disease progression and poor prognosis [4-6]. Cell line studies have shown that by blocking HER1/EGFR tyrosine kinase signaling by addition of TKIs to gemcitabine, it decreases the growth of BTC and improves the anticancer effect of gemcitabine [7]. Erlotinib a firstgeneration EGFR TKI is currently approved for patients with non-small cell lung cancer and first line of treatment for metastatic or locally advanced pancreatic cancer in combination with gemcitabine [8].

Oxaliplatin differs in pharmacokinetics and dynamics from other platinum derivatives, like cisplatin and carboplatin, and has been used in combination with gemcitabine in clinical studies [9].

Gene sequencing has identified EGFR mutations in East Asians never smokers, and women having adenocarcinomas [10]. Retrospective studies show that $80 \%$ of patients with EGFR mutant non-small cell lung cancer (NSCLC) tumors treated with EGFR TKIs show radiographic and clinical responses with better progression free survival (PFS) and overall survival (OS) compared to wild type [11, 12]. Results of the studies show that not all tumors with activating EGFR mutations respond to EGFR inhibitors. Activation of EGFR also occurs with exon 20 inframe base pair insertions; however, this is also associated with de novo resistance to EGFR TKIs [13, 14].

Review of literature revealed a handful of studies that has evaluated the effect of erlotinib in EGFR-mutated GBC patients. A randomized phase III study showed that addition of erlotinib to gemcitabine and oxaliplatin enhances antitumor activity, which might become a treatment option for patients with cholangiocarcinoma [15]. Another phase II study showed that combining sorafenib and erlotinib does not improve response rate in BTC advocating patient selection based on molecular markers [3]. A case of stage IV gallbladder cancer with no EGFR mutation having long complete response to treatment with EGFR-TKI plus chemotherapy has been reported [16]. Therefore, addition of erlotinib to standard therapy may provide a more efficacious treatment for $\mathrm{GBC}$ patients with metastasis.

In the present case, next generation sequencing (NGS) was performed and analyzed in terms of mutations, amplifications, and over expression. The following is the first case report demonstrating the effect of erlotinib with gemcitabine-oxaliplatin regimen in a EGFR-mutated (exon 20 T790M) GBC patient with liver metastasis which showed a complete radiologial response to liver metastasis and $90 \%$ partial response in primary disease, with 11 months PFS.

\section{Case report}

In July 2019, a 60-year-old female presented with chief complaint of abdominal pain and loss of appetite for 1 month in surgical oncology OPD of Sir Sundarlal Hospital, Institute of Medical Sciences, Banaras Hindu University (Varanasi-India). There was no history of comorbidities like diabetes, hypertension, tuberculosis or asthma, and also did not have icterus. There was no past history of surgical treatment. Physical examination revealed mild right hypochondriac tenderness. Contrast enhanced computed tomography (CECT) revealed gallbladder (GB) distension, calculus, calcification of GB wall, irregular inhomogenously enhancing GB wall thickening, and multiple hypo-dense lesions in both lobes of the liver, multiple enlarged mesenteric and peripancreatic lymph nodes (Fig. 1a-c). Image-guided biopsy revealed adenocarcinoma of gallbladder. Routine complete blood count and serum biochemistry were within normal limits, whereas CA 19-9 level was 39.2 (upper limit of normal $35 \mathrm{IU} / \mathrm{mL}$ ). Patient was advised for next generation sequencing (NGS) which came positive for Tp53 (exon 7-c.713 G > A and exon 5-c.376$2 \mathrm{~A}>\mathrm{G}$ ) and EGFR (exon 20-T790M).

\section{Treatment regimen and results}

Initially, patient was treated with two cycles of fixed rate gemcitabine $1 \mathrm{gm} / \mathrm{m}^{2}$ administered on day 1 and day 8 and oxaliplatin $100 \mathrm{mg} / \mathrm{m}^{2}$ intra venous on day 1 every 21 days. From 3rd cycle onwards after assessment of NGS report, a daily dose of erlotinib $150 \mathrm{mg}$ was added to above mentioned treatment regime up to 6 cycles of chemotherapy which concluded in January 2020. After completion of chemotherapy, a CECT scan of abdomen was performed. It showed no evidence of disease in the liver having normal size, shape, outline, and CT attenuation (Fig. 2a), showing a complete radiological response as per RECIST criteria. GB showed multiple calculi in lumen, eccentric wall thickening in fundo-body region infiltrating segment IVB and V of liver (Fig. 2a-b) suggesting 90\% response as per RECIST. CA19-9 at this juncture was 17.3. During the course of the disease, grade I neutropenia and grade I skin rashes were seen. Patient was shifted to maintenance therapy with capecitabine $1500 \mathrm{mg}$ in divided doses for 14 days and erlotinib $150 \mathrm{mg}$ per oral once daily. Patient is tolerating the treatment well and has not shown any further disease progression 11 months after initiation of treatment.

\section{Discussion}

The above case displays the efficacy of combination of erlotinib with gemcitabine and oxaliplatin in treating a EGFR-mutated GBC with liver metastasis. From the past two decades, erlotinib has been gaining considerable attention in the field of cancer therapeutics. There is documentation of few intriguing studies, which are elementary to further research in this concern. In a randomized phase III study, Lee et al. compared 133 patients 


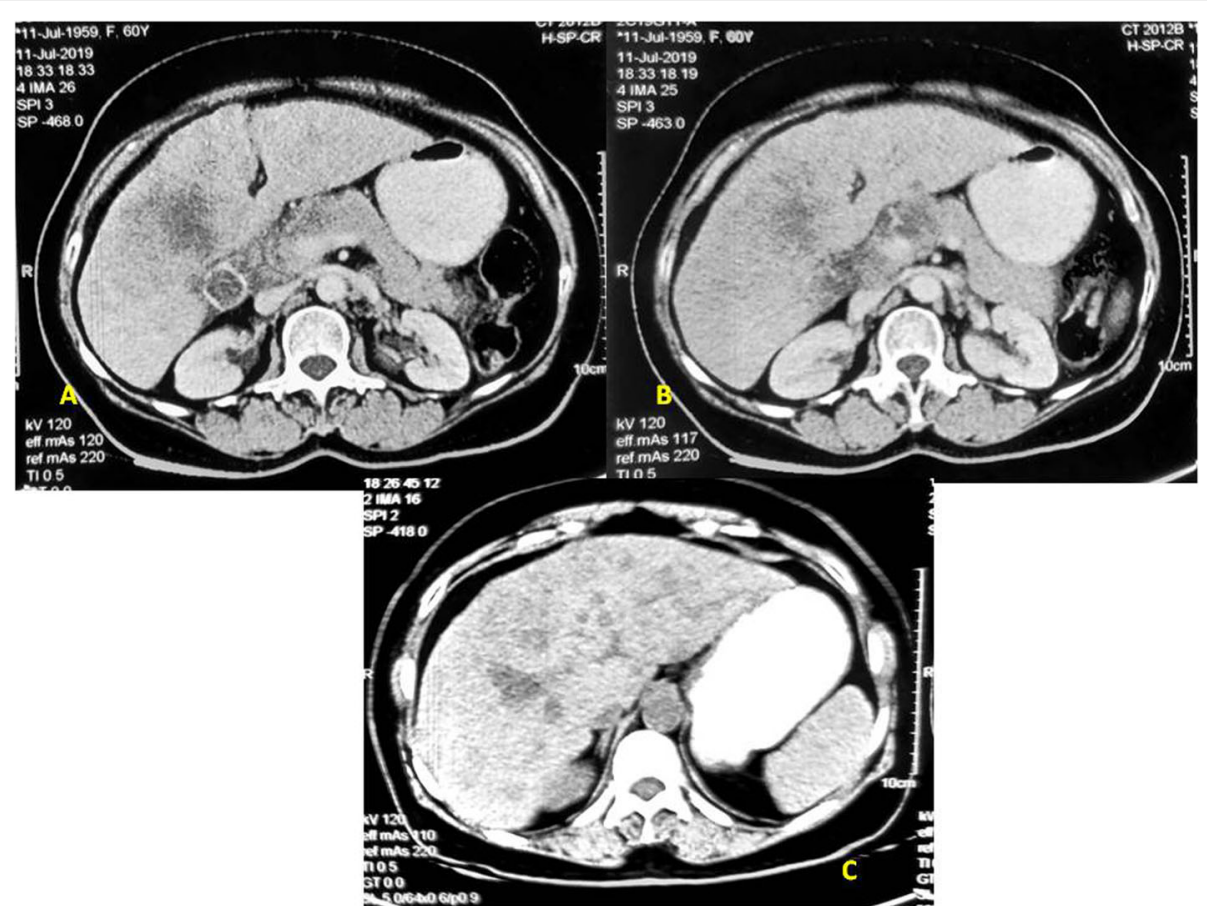

Fig. 1 Pretreatment CT scan showing a mass in the fundus of gallbladder infiltrating IVB, V segment of liver with gallstones. b Liver metastasis with periportal and precaval lymphadenopathy. c Extensive liver metastasis

receiving only chemotherapy with 135 patients receiving chemotherapy in combination with erlotinib. The median PFS was 4 months versus 5.8 months. In patients with cholangiocarcinoma, the combination resulted in better PFS compared to GBC suggesting molecular differences between two cancer subtypes [15]. Mody et al. reported a complete remission by the fourth cycle of therapy in a case of metastatic, wild-type EGFR, gallbladder cancer infiltrating liver with lymph node metastasis treated with gemcitabine and erlotinib, and the treatment was continued for 12 cycles. They suggested that future studies of EGFR-TKI therapy plus chemotherapy in patients with BTCs should not be restricted only to those patients with EGFR mutations [16].
The “first-generation' EGFR inhibitors, i.e., gefitinib and erlotinib, are reversible, ATP-competitive inhibitors that target exon 19 deletion and L858R mutant EGFR selectively and have been used in the treatment of EGFR-mutant NSCLC and pancreatic cancer, achieving up to a $72 \%$ response rate (RR) and nearly 10 months PFS [17-19]. A second exon 20, T790M mutation in EGFR, in patients already receiving first generation TKI, accounts for nearly half of the acquired resistance to first-generation TKI [20-23]. The proposed mechanism of resistance is steric hindrance imposed by the presence of a methionine residue preventing the binding of firstgeneration TKI to EGFR. However, further studies

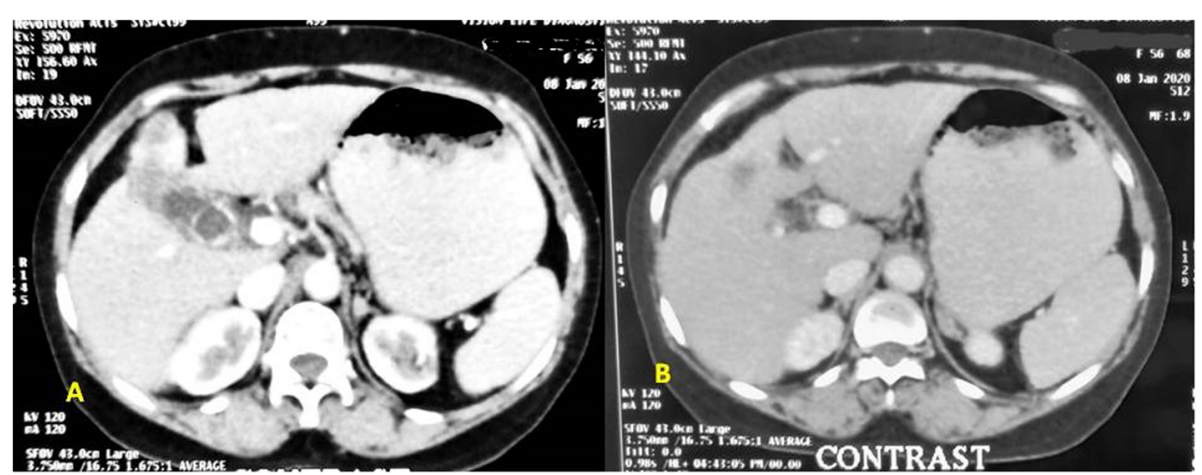

Fig. 2 Post treatment scan showing a residual mass in the fundus of gallbladder with normal liver and $\mathbf{b}$ residual mass in segment $\mathrm{V}$ of gallbladder with normal liver and absence of nodes 
showed that the affinity of the mutant EGFR receptor to gefitinib is decreased but the binding is not completely inhibited [24, 25]. In 2013, a case of adenocarcinoma lung with EGFR exon 20 insertion A763_Y764insFQEA has been reported, which was responsive to erlotinib that was added to gemcitabine, docetaxel, and vinorelbine regimen.

Our case being GBC with T790M mutation in EGFR exon 20 showed a near complete response and prolonged PFS, with the use of first generation EGFR TKI erlotinib added to the gemcitabine-oxaliplatin regimen, which is a significant phenomenon. We cannot attribute the observed response solely to treatment with erlotinib, and erlotinib when added to gemcitabine has been shown to increase its efficacy and that could have resulted in response in this case. In BTC, a 13-15\% EGFR mutation has been reported suggesting that only such patients be enrolled in clinical trials $[26,27]$. Iyer et al. showed that patients with KRAS (G12V) mutation do not respond to treatment and should be excluded, but, the same was not found for KRAS (G13D) mutation [28]. There is still uncertainity over the exact mechanism and role of these mutations and response to EGFR TKI's, further detailed studies, and clinical trials with large sample size and improvised patient selection are required to confirm such benefits of the treatment for GBC.

\section{Conclusions}

The present case report demonstrates a complete response in liver metastasis and $90 \%$ partial response to primary disease in the presence of a tumor-associated EGFR mutation in patient with metastatic gallbladder cancer. Our findings highlight the clinical response in EGFR exon 20, T790M mutations with EGFR TKI erlotinib in combination with chemotherapy. Even though it cannot be concluded that this response is solely due to addition of erlotinib, nonetheless, it strengthens the need for future studies of EGFR-TKI therapy plus chemotherapy in patients with GBC in patients with EGFR mutations.

\section{Acknowledgements}

None

\section{Authors' contributions}

KS did the literature search and prepared the draft manuscript. TK helped in preparation of manuscript and edited the manuscript for scientific content. MP conceived and designed the study and edited the final manuscript. All authors read and approved the final manuscript.

\section{Funding}

None
Ethics approval and consent to participate

Ethical approval is not required as patient consent for publication was obtained.

\section{Consent for publication}

The written consent for publication of case report and accompanied images was obtained from the patient.

\section{Competing interests}

The authors declare that there are no competing interests

Received: 21 May 2020 Accepted: 23 June 2020

Published online: 04 July 2020

References

1. Xiu AX, Hong TS, Hezel AF, Kooby DA. Current management of gallbladder carcinoma. Oncologist. 2010;15:168-81.

2. Valle J, Wasan $\mathrm{H}$, Palmer $\mathrm{DH}$, et al. Cisplatin plus gemcitabine versus gemcitabine for biliary tract cancer. N Engl J Med. 2010;362:1273-81.

3. El-Khoueiry AB, Rankin C, Siegel AB, lqbal S, Gong IY, Micetich KC, Kayaleh OR, Lenz HJ, Blanke CD. S0941: a phase 2 SWOG study of sorafenib and erlotinib in patients with advanced gallbladder carcinoma or cholangiocarcinoma. Br J Cancer 2014 Feb 18;110(4):882-887. doi: https:// doi.org/10.1038/bjc.2013.801.Epub 2014 Jan14. PMID: 24423918.

4. Li M, Zhang Z, Li X, Ye J, Wu X, Tan Z, Liu C, Shen B, Wang XA, Wu W, Zhou D, Zhang D, Wang T, Liu B, Qu K, Ding Q, Weng H, Ding Q, Mu J, Shu Y, Bao R, Cao Y, Chen P, Liu T, Jiang L, Hu Y, Dong P, Gu J, Lu W, Shi W, Lu J, Gong W, Tang Z, Zhang Y, Wang X, Chin YE, Weng X, Zhang H, Tang W, Zheng Y, He L, Wang H, Liu Y, Liu Y. Whole-exome and targeted gene sequencing of gallbladder carcinoma identifies recurrent mutations in the ErbB pathway. Nat Genet. 2014 Aug;46(8):872-876. doi: https://doi.org/10.1038/ng.3030. Epub 2014 Jul 6. PMID: 24997986.

5. Peraldo-Neia C, Cavalloni G, Fenocchio E, Cagnazzo C, Gammaitoni L, Cereda S, Nasti G, Satolli MA, Aprile G, Reni M, Avallone A, Spadi R, Venesio T, Martin V, Doglioni C, Frattini M, Aglietta M, Leone F. Prognostic and predictive role of EGFR pathway alterations in biliary cancer patients treated with chemotherapy and anti-EGFR. PLoS One 2018 Jan 19;13(1):e0191593. doi: https://doi.org/10.1371/journal.pone.0191593. eCollection 2018. PMID: 29352306.

6. Sharma A, Kumar A, Kumari N, Krishnani N, Rastogi N. Mutational frequency of KRAS, NRAS, IDH2, PIK3CA, and EGFR in north Indian gallbladder cancer patients. Ecancermedicalscience. 2017 Aug 7;11:757. doi: https://doi.org/10. 3332/ecancer.2017.757. eCollection2017. PMID: 2890047.

7. Pignochino Y, Sarotto I, Peraldo-Neia C, Penachioni JY, Cavalloni G, Migliardi G, Casorzo L, Chiorino G, Risio M, Bardelli A, Aglietta M, Leone F. Targeting EGFR/HER2 pathways enhances the antiproliferative effect of gemcitabine in biliary tract and gallbladder carcinomas. BMC Cancer. 2010 Nov 18;10:631. doi: https://doi.org/10.1186/1471-2407-10-631.PMID: 21087480.

8. Tarceva prescribing information. https://www.gene.com/download/pdf/ tarceva_prescribing.pdf. Accessed 3 July 2020.

9. Mathe G, Kidani Y, Segiguchi M, et al. Oxalato-platinum or 1-OHP, a thirdgeneration platinum complex: an experimental and clinical appraisal and preliminary comparison with cis-platinum and carboplatinum. Biomed Pharmacother. 1989:43:237-50.

10. Shigematsu H, Lin L, Takahashi T, et al. Clinical and biological features associated with epidermal growth factor receptor gene mutations in lung cancers. J Natl Cancer Inst 2005;97:339-346. [PubMed: 15741570].

11. Sequist LV, Bell DW, Lynch TJ, Haber DA. Molecular predictors of response to epidermal growth factor receptor antagonists in non-small-cell lung cancer. J Clin Oncol 2007;25:587-595. [PubMed: 17290067].

12. Mitsudomi T, Kosaka T, Endoh $\mathrm{H}$, et al. Mutations of the epidermal growth factor receptor gene predict prolonged survival after gefitinib treatment in patients with non-small-cell lung cancer with postoperative recurrence. J Clin Oncol 2005;23:2513-2520. [PubMed: 15738541].

13. Arcila ME, et al. EGFR exon 20 insertion mutations in lung adenocarcinomas: prevalence, molecular heterogeneity, and clinicopathologic characteristics. Mol Cancer Ther. 2013;12:220-9.

14. Kobayashi Y, Mitsudomi T. Not all epidermal growth factor receptor mutations in lung cancer are created equal: perspectives for individualized treatment strategy. Cancer Sci. 2016;107:1179-86. 
15. Lee, J., Park, S. H., Chang, H. M., Kim, J. S., Choi, H. J., Lee, M. A., Chang, J. S. Jeung, H. C., Kang, J. H., Lee, H. W., Shin, D. B., Kang, H. J., Sun, J. M., Park, J. O., Park, Y. S., Kang, W. K., \& Lim, H. Y. (2012). Gemcitabine and oxaliplatin with or without erlotinib in advanced biliary-tract cancer: a multicentre, open-label, randomised, phase 3 study. Lancet Oncol, 13(2), 181-188. https://doi.org/https://doi.org/10.1016/S1470-2045(11)70301-1.

16. Mody K, Strauss E, Lincer R, Frank RC. Complete response in gallbladder cancer to erlotinib plus gemcitabine does not require mutation of the epidermal growth factor receptor gene: a case report. BMC Cancer. 2010;10: 570. Published 2010 Oct 20. doi:https://doi.org/10.1186/1471-2407-10-570.

17. Rosell $R$, et al. Erlotinib versus standard chemotherapy as first-line treatment for European patients with advanced EGFR mutation-positive non-small-cell lung cancer (EURTAC): a multicentre, open-label, randomised phase 3 trial. Lancet Oncol. 2012;13:239-46.

18. Hirsch FR, et al. Molecular predictors of outcome with gefitinib in a phase III placebo-controlled study in advanced non-small-cell lung cancer. J Clin Oncol. 2006;24:5034-42.

19. Mok TS, et al. Gefitinib or carboplatin-paclitaxel in pulmonary adenocarcinoma. N Engl J Med. 2009;361:947-57.

20. Kosaka T, et al. Analysis of epidermal growth factor receptor gene mutation in patients with non-small cell lung cancer and acquired resistance to gefitinib. Clin Cancer Res. 2006;12:5764-9.

21. Lynch TJ, Bell DW, Sordella R, Gurubhagavatula S, Okimoto RA, Brannigan $\mathrm{BW}$, et al. Activating mutations in the epidermal growth factor receptor underlying responsiveness of non-small-cell lung cancer to gefitinib. N Engl J Med. 2004; 350(21):2129-2139. https://doi.org/https://doi.org/10.1056/ NEJMoa040938 PMID: 15118073.

22. Paez JG, Janne PA, Lee JC, Tracy S, Greulich H, Gabriel S, et al. EGFR mutations in lung cancer: correlation with clinical response to gefitinib therapy. Science. 2004; 304(5676):1497-1500. https://doi.org/https://doi.org/ 10.1126/science.1099314 PMID: 15118125.

23. Pao W, Miller V, Zakowski M, Doherty J, Politi K, Sarkaria I, et al. EGF receptor gene mutations are common in lung cancers from "never smokers" and are associated with sensitivity of tumors to gefitinib and erlotinib. Proc Natl Acad Sci U S A. 2004; 101(36):13306-13311. https://doi.org/https://doi.org/ 10.1073/pnas.0405220101 PMID: 15329413.

24. Yun $\mathrm{C}-\mathrm{H}$, et al. The T790M mutation in EGFR kinase causes drug resistance by increasing the affinity for ATP. Proc Natl Acad Sci. 2008;105:2070-5.

25. Eck MJ, Yun CH. Structural and mechanistic underpinnings of the differential drug sensitivity of EGFR mutations in non-small cell lung cancer. Biochim Biophys Acta. 2010;1804:559-66.

26. Gwak G-Y, Yoon J-H, Shin CM, Ahn YJ, Chung JK, Kim YA, et al. Detection of response-predicting mutations in the kinase domain of the epidermal growth factor receptor gene in cholangiocarcinoma. J Cancer Res Clin Oncol. 2005;131:649-62.

27. Leone F, Cavalloni G, Pignochino Y, Sarotto I, Ferraris R, Piacibello W, et al. Somatic mutations of epidermal growth factor receptor in bile duct and gallbladder carcinoma. Clin Cancer Res. 2006;12:1680-5.

28. Iyer P, Shrikhande SV, Ranjan M, et al. ERBB2 and KRAS alterations mediate response to EGFR inhibitors in early stage gallbladder cancer. Int J Cancer. 2019;144(8):2008-19. https://doi.org/10.1002/ijc.31916.

\section{Publisher's Note}

Springer Nature remains neutral with regard to jurisdictional claims in published maps and institutional affiliations.

Ready to submit your research? Choose BMC and benefit from:

- fast, convenient online submission

- thorough peer review by experienced researchers in your field

- rapid publication on acceptance

- support for research data, including large and complex data types

- gold Open Access which fosters wider collaboration and increased citations

- maximum visibility for your research: over $100 \mathrm{M}$ website views per year

At BMC, research is always in progress.

Learn more biomedcentral.com/submissions 